\title{
Paediatric lung transplantation: the agony and the ecstasy
}

The introduction of cyclosporin A into clinical practice ${ }^{1}$ catalysed a huge resurgence of interest in cardiothoracic transplantation, and enabled Reitz et al at Stanford to perform the first successful heart-lung transplant for pulmonary vascular disease in $1981 .^{2}$ Thereafter this treatment was offered to patients with cystic fibrosis who followed similar post-transplantation courses, despite early concerns of recurrence of the original disease and sepsis in the allograft. . $^{3-6}$

Single and double lung transplantation were later developed for adults with diagnoses including emphysema and fibrotic lung disease, thereby increasing the pool of recipients. $^{78}$ The 1992 Registry of the International Society for Heart and Lung Transplantation reported that over 2200 lung transplants (all types) had been performed worldwide, with an actuarial survival ranging from $59 \%$ at one year to $42 \%$ at five years. ${ }^{9}$

Few data regarding lung transplantation in children have been published, although it appears that mortality and morbidity may be greater in this younger age group. ${ }^{1011}$ The following discourse relates to a five year experience with combined heart-lung transplantation in children and adolescents at The Hospital for Sick Children, London. Although this relates specifically to heartlung transplantation, it remains applicable to all types of paediatric lung transplantation.

At this institute, up to June 1993 a total of 160 patients have been assessed of whom 32 have received transplants. As with earlier experience, ${ }^{12}$ most of the patients referred for assessment had cystic fibrosis, representing $75 \%$ of the total cohort.

\section{The agony}

Anxiety for both child and family may accompany the initial referral for heart-lung transplantation. This may be related to the fear of being "unacceptable" for transplantation, but possibly more simply a fear of the unknown - that is, different centre and staff, a new form of treatment, etc. The four day admission for transplantation assessment and preparation can be arduous and disquietening. The media, rightly, extol the positive aspects of transplantation but, in so doing, may misrepresent this form of treatment. Many believe that transplantation is simply a surgical procedure effecting a permanent cure, and are dismayed at the prospect of lifelong immunosuppression therapy with all its attendant risks. In addition, the prospect of short and long term complications, including acute and chronic rejection, infection, change in body appearance and, ultimately, premature death, induce further distress.

One of the selection criteria is a prognosis of less than two years. The realisation that the child's life expectancy is therefore reduced to this time scale once accepted for transplantation may present emotional difficulties for the family. These concerns may be exacerbated whilst awaiting transplantation as the "countdown" proceeds. This may produce further psychosocial morbidity while accelerated clinical deterioration has also been observed. ${ }^{13}$

As a result of the limited number of suitable donor organs, more transplant centres, and a rise in the number of patients awaiting lung transplantation, we have noted a greater attrition rate in those waiting and a greater waiting period to transplantation. At our institute 49 children, representing $48 \%$ of those accepted, have died whilst awaiting transplantation, while the mean time to transplantation has increased from a previously reported 3.3 months in $1990^{12}$ to over 10 months in 1993.

As pressure to transplant mounts, suboptimal donors may be considered; potential recipients are often called in and then disappointed when the donor has eventually been declined. These aborted trips - which may number two or even three - add to the overall emotional burden of the family, which may also be compounded by the many false alarms raised by the accidental sounding of the omnipresent pager. Warner described this as an "exquisite form of torture" for the rapidly deteriorating child and, in addition, was concerned by the inappropriate avoidance of palliative care. ${ }^{14}$

We have been fortunate to have experienced a relatively low early postoperative ( $<30$ days) mortality $(6 \%)$ and, accordingly, the actual period after surgery has often been one of cautious euphoria and high expectations. However, all recipients endure at least one episode of acute pulmonary rejection within the first two postoperative weeks. Many continue to have recurrent rejection and, in parallel with the increasing levels of immunosuppression administered, so too the risks of pathogenic and opportunistic infections increase.

Rejection and infection of the lung allograft, together with other insults including ischaemia and lung denervation, may contribute to the development of obliterative bronchiolitis. ${ }^{15}$ This devastating condition accounts for much of the later morbidity and mortality experienced by lung transplant recipients of all ages. In this cohort its occurrence has been observed as early as two months after transplantation, with a definite population afflicted within the first year. This early onset obliterative bronchiolitis appears to represent a clinically more aggressive form of the disease than that which occurs later, although both show identical histology. ${ }^{16}$

With disease progression patients develop worsening air flow obstruction associated with hypoxia, and are prone to infective exacerbations related to the development of a central bronchiectasis. Regrettably, actuarial freedom from obliterative bronchiolitis in those surviving to three years is only $37 \%$. Attempts to halt or at least attenuate this pathological process by medical therapy have proved unsatisfactory, ${ }^{17}$ and the only definitive treatment is retransplantation. Results for the latter have so far been disappointing. ${ }^{118}$ Naturally, therefore, patients and families are devastated once the diagnosis of obliterative bronchiolitis has been established and the limited treatment options explored.

Changes in body appearance induced by immunosuppression therapy - that is, hypertrichosis and gingival hypertrophy with cyclosporin A; cushingoid features with steroids, etc - may become intolerable for adolescent patients. This has resulted in non-compliance with the therapeutic regimen, producing a significant deterioration in graft function. As with paediatric renal transplantation, non-compliance may be a major cause (up to $27 \%$ ) of late graft loss. ${ }^{19}$

\section{The ecstasy}

Even though the realisation of a limited prognosis may create anxiety, this is often outweighed by the optimism engendered by the patient being accepted onto an active 
waiting list for transplantation. For many it represents a chance that the life of the child will be extended, that the quality of life will improve and, particularly for those afflicted with cystic fibrosis, that a "normal" existence may be experienced for the very first time. We have even observed an improvement in the clinical status of some patients following acceptance for this procedure, presumably secondary to this overwhelming optimism.

There is no doubt that, for those receiving transplants, actuarial survival to three years is improved and is currently $63 \%(95 \%$ confidence interval: $42 \%-78 \%)$ at one year; $54 \%(95 \% \mathrm{CI}: 33 \%-71 \%)$ at two years; and $48 \%$ (95\% CI: $27 \%-66 \%$ ) at three years. ${ }^{16}$ This compares with $100 \%$ mortality at two years for those not transplanted. For most, these odds for short and medium term survival are enough to become fully committed to transplantation.

There are few instances in clinical practice that compare with the transformation of a chair-ridden, oxygendependent, cachectic youngster to a vigorous, active individual within weeks or even days of successful transplantation. At one year after transplantation most survivors enjoy an excellent quality of life afforded to them by this superior clinical status. In patients with cystic fibrosis, for example, pulmonary function, as measured by $\mathrm{FEV}_{1}$, was increased from a mean of $25 \%$ (percentage of predicted normal) before transplantation to $74 \%$ at one year after transplantation, enabling an elevated level of sporting activity and return to full time school.

These benefits to the transplanted patient also have positive implications for other family members. With a reduction in the time spent administering treatment, families have time to pursue more enjoyable activities. This has often led to an improvement in family functioning and a significant diminution in the level of parental stress.

\section{The future}

Current thrusts to improve the efficacy of lung transplantation include increasing the number of available donors, the development of more effective and selective immunosuppressive agents, and prevention of obliterative bronchiolitis. Methods to increase the number of suitable donor organs will hopefully lead to more children being transplanted, a reduction in the attrition rate of those waiting and, accordingly, greater "ecstasy" associated with this treatment. In the UK this has included a Department of Health and Royal College of Surgeons initiative to zone potential donor populations to major transplant centres and create multiorgan donor retrieval teams. Potential benefits of such a scheme include improved donor care, leading to harvesting the maximum number of potential donor lungs.

Another method of increasing the donor pool would be to introduce an "opting out/presumed consent" rather than the present "opting in" policy for the donation of organs. This currently occurs in other European countries including France, Austria, and Belgium. Much debate has been generated concerning the ethics of such a change in policy. However, we feel that increasing public awareness of actively consenting to organ donation is ethically and morally more acceptable.

A further option to increase the donor pool is to use living related donors. Vaughn Starnes, formerly at Stanford and now in Los Angeles, has pioneered lobar transplantation from living related donors into children with end stage pulmonary parenchymal or vascular disease. ${ }^{20}$ This constitutes an exciting advance in the field of lung transplantation, but the ethics of such a procedure are even more complex than those associated with the "opting out/presumed consent" issue and will probably prevent widespread utilisation. ${ }^{21}$
Another possible source of organs is from non-human donors - that is, xenotransplantation. To date clinical xenografting of heart ${ }^{22}$ and liver ${ }^{23}$ have not permitted long term survival because of the development of an uncontrollable form of humoral rejection, the usual accompaniment of cross-species transplantation. Immunosuppression regimens have been developed to overcome this humoral form of rejection and have enabled successful experimental xenografting. ${ }^{24}$

Another exciting prospect has been developed by White et al at Cambridge. They have successfully bred transgenic mice expressing a human cell surface molecule (decay accelerating factor, DAF) which deactivates human complement. ${ }^{25}$ This may abrogate the humorally mediated hyperacute rejection observed in xenotransplantation. A transgenic pig model is also being developed for possible future clinical use.

There is a plethora of new immunosuppressive agents currently progressing through various trial phases which may potentially have a similar impact on clinical lung transplantation in the 1990 s as cyclosporin A has had over the past decade. Some of these include FK506, Rapamycin, RS16443, and more specific monoclonal antibody therapies. ${ }^{26}$ The ideal agent is one which induces immunological tolerance of the allograft without over-immunocomprising the recipient, thereby limiting the risks of opportunistic infection, malignancy, or both. With improved more selective agents the devastating problem of obliterative bronchiolitis may also be surmountable.

In genetically determined conditions such as cystic fibrosis the evolution of replacement gene therapy ${ }^{27}$ may prevent or even reverse the severe pulmonary complications associated with this disease, thereby eliminating altogether the need for lung transplantation. The efficacy of this treatment remains to be determined, however, and, until then, lung transplantation will be used for end stage pulmonary complications of cystic fibrosis as well as for other pulmonary diseases. Our goal therefore is to maximise the benefits of transplantation by increasing both the quantity and quality of survival and, like Michelangelo, revel in the ecstasy of having created a therapeutic masterpiece.

The authors wish to thank Miss A McGregor for preparation of the manuscript.

Cardiothoracic Unit,

The Hospital for Sick Children,

Great Ormond Street,

London $W C 1 N 3 \mathcal{F H}$

1 Borel JF, Kis ZL. The discovery and development of Cyclosporine (Sandimmune). Transplant Proc 1991;23:1867-74.

2 Reitz BA, Wallwork JL, Hunt SA, Pennock JL, Billingham ME, Oyer PE, et al. Heart-lung transplantation. Successful therapy for patients with pulmonary vascular disease. $N$ Engl $\mathcal{f}$ Med 1982;306:557-64.

3 Scott J, Higenbottam T, Hutter J, Hodson M, Stewart S, Penketh A, et al. Heart-lung transplantation for cystic fibrosis. Lancet 1988;ii:192-4.

4 Wood A, Higenbottam T, Jackson M, Scott J, Stewart S, Wallwork J Airway mucosal bioelectric potential difference in cystic fibrosis after lung Airway mucosal bioelectric potential difference in cystic

5 De Leval MR, Smyth R, Whitehead B, Scott JP, Elliott MJ, Sharples L, et al. Heart and lung transplantation for terminal cystic fibrosis. A 4.5 year al. Heart and lung transplantation for terminal cystic fib

6 Starnes VA, Lewiston N, Theodore J, Stoehr C, Stinson E, Shumway NC et al. Cystic fibrosis. Target population for lung transplantation in North et al. Cystic fibrosis. Target population for lung transplantation in North America in the 1990s. $\mathcal{F}$ Thorac Cardiovasc Surg 1992;103:1008-14. Toronto lung transplant group. Unilateral lung
ary fibrosis. $N$ Engl $f$ Med 1986;314:1140-5.

8 Cooper JD, Patterson GA, Grossman R, Maurer J. Double lung transplant for advanced chronic obstructive lung disease. Am Rev Respir Dis 1989;139:303-7.

9 Kaye MP. The registry of the International Society for Heart and Lung Transplantation: ninth official report - 1992. F Heart Lung Transplant 1992;11:599-606.

10 Whitehead B, Helms P, Goodwin M, Martin I, Scott JP, Smyth RL, et al. Heart-lung transplantation for cystic fibrosis. II: Outcome. Arch Dis Child 1991;66:1022-6.

11 Metras D, Kreitmann B, Shennib H, Noirclerc $M$. Lung transplantation in children. 7 Heart Lung Transplant 1992;11:S282-5. 
12 Whitehead B, Helms P, Goodwin M, Lask B, Serrano E, Scott JP, et al. Heart-lung transplantation for cystic fibrosis. I: Assessment. Arch Dis Child 1991;66:1018-21.

13 Gold LM, Kirkpatrick BS, Fricker FJ, Zitelli BJ. Psycho-social issues in paediatric organ transplantation: the parents' perspective. Pediatrics 1986;77:738-44.

14 Warner JO. Heart-lung transplantation: all the facts. Arch Dis Child 1991;66:1013-7.

15 Burke CM, Glanville AR, Theodore J, Robin ED. Lung immunogenicity, rejection and obliterative bronchiolitis. Chest 1987;92:547-9.

16 Whitehead B, Rees P, Sorensen K, Bull C, Higenbottam TW, Wallwork J, et al. Incidence of obliterative bronchiolitis following heart-lung transplantation in children. F Heart Lung Transplant 1993;12:903-8.

17 Glantation in children. f Heart Lung Transplant 1993;12:903-8. bronchiolitis after heart-lung transplantation; apparent arrest by augbronchiolitis after heart-lung transplantation; apparent arres

18 Novick RJ, Kaye MP, Patterson GA, Andreassian B, Klepetko W, Menkis $\mathrm{AH}$, et al. Redo lung transplantation: a North American-European experience. F Heart Lung Transplant 1993;12:5-16.

19 Dunn J, Golden D, Van Buren CT, Lewis RM, Lawen J, Kahan BD. Causes of graft loss beyond two years in the cyclosporine era. Transplantation 1990;49:349-53.
20 Starnes VA. Lobar transplantation: indication and outcome. 7 Heart Lung Transplant 1993;12:S94

21 Shaw LR, Miller JD, Slutsky AS, Maurer J, Puskas JD, Patterson GA, e al. Ethics of lung transplantation with live donors. Lancet 1991;338: 678-81.

22 Bailey LL, Nehlsen-Cannarella SL, Concepcion W, Jolley WB. Baboon-tohuman cardiac xenotransplantation in a neonate $\mathcal{F} A M A$ 1985;254: 3321-9.

23 Starzl TE, Fung J, Tzakis A, Todo S, Demetris AJ, Marino IR, et al. Baboon to human liver transplantation. Lancet 1993;341:65-71.

24 Hasam RIR, Sriwatanawongsa V, Wallwork J, White DJG. Consistent prolonged "concordant" survival of hamster-to-rat cardiac xenografts by prolonged "concordant" survival of hamster-to-rat cardiac xenografts by 1993;25:421-2.

25 Cary N, Moody J, Yannoutsos N, Wallwork J, White D. Tissue expression of human decay accelerating factor, a regulator of complement activation expressed in mice: a potential approach to inhibition of hyperacute xenograft rejection. Transplant Proc 1993;25:400-1.

26 Kahan BD. Immunosuppressive therapy. Curr Opin Immunol 1992;4: 553-60.

27 Coutelle C, Caplen N, Hart S, Huxley C, Williamson R. Gene therapy for cystic fibrosis. Arch Dis Child 1993;68:437-43. 